\title{
Ni-Catalyzed Alkylative Dimerization of Vinyl Grignard Reagents Using Alkyl Fluorides
}

$$
\mathrm{MgCl}_{\mathrm{MgCl}}^{\mathrm{n} \text {-Octyl-F }} \stackrel{3 \mathrm{~mol} \% \mathrm{NiCl}_{2}\left(\mathrm{PPh}_{3}\right)_{2}}{\mathrm{THF}, 25{ }^{\circ} \mathrm{C}, 7 \mathrm{~h}}
$$

Significance: For this reaction, alkyl fluorides were found superior as alkylating agents than alkyl chlorides and iodides. Vinylmagnesium chloride serves here as a useful C4-synthon for the construction of a branched carbon skeleton, potentially applicable in various synthetic schemes.
Comment: This approach will be useful for the synthesis of complex molecules and natural products. Alkyl fluorides are usually inert during the most synthetic transformations, thus serving as a 'protection' group before being activated by this method. The reaction itself looks very promising as a new tool for selective $\mathrm{C}-\mathrm{C}$ bond formation. The tentative mechanism includes the formation of cyclic (2-butene-1,4-diyl)magnesium by reductive coupling of two vinyl moieties on the Ni center, which react further with alkyl fluorides. 